\title{
Relevance of Position and Movement of the Gastroesophageal Junction in Gastroesophageal Reflux Disease
}

TO THE EDITOR: Gastroesophageal reflux disease (GERD) and its complications are increasingly recognized in many parts of Asia, largely due to an increasing prevalence of obesity. Obese subjects are found to have frequent transient lower esophageal sphincter (LES) relaxations (TLESRs) and more likely to reflux ${ }^{1}$ with underlying mechanisms being unclear. Besides the circular muscle, recent evidence suggests a role for longitudinal muscle in the opening of lower sphincter, ${ }^{2}$ which may be relevant in the pathogenesis of GERD. Kim and colleagues ${ }^{3}$ utilized high-resolution manometry to characterize TLESRs especially esophageal movement which they hypothesized to be different in patients with GERD from in controls. The study, however did not suggest a difference in degree of esophageal shortening using LES lift. There were a number of limitations which might explain the negative results, some that had been addressed in the paper.

The study did not assess the presence of hiatus hernia which is an anatomical defect of the gastroesophageal junction (GEJ), commonly present in severe form of GERD. More recent evidence, using a novel Hall-effect technique that allows continuous measurement of the location of the GEJ without the need for fluoroscopy, indicates that TLESRs are a severe but transient form of hiatus herniation. ${ }^{4,5}$ Furthermore, partial hiatus hernia is likely to be common especially in the presence of obesity and raised intra-abdominal pressure. ${ }^{6}$ High-resolution manometry is able to discern the separation of pressure components of the $\mathrm{LES}^{7}$ which is a sign of hiatus hernia but the sensitivity is poor. LES lift is a poor measure of esophageal shortening, not sensitive during complete TLESR or hiatus hernia and a small movement may not be detected. ${ }^{8}$ A reliable knowledge of position of the GEJ is also relevant especially with regards to the acid pocket, which is an area of unbuffered postprandial gastric acidity, immediately distal to the GEJ. ${ }^{9}$ Acid pocket is enlarged in hiatus hernia and it provides a reservoir of acid available to reflux whenever the intrinsic sphincter fails. ${ }^{9}$

To conclude, there are unanswered questions on the exact mechanisms underlying GERD but 2 points may be of interest. ${ }^{10}$ One is whether hiatus hernia represents the severe end of a spec- trum to the degree of proximal displacement of the GEJ relative to the diaphragm and whether mild reflux disease is related to mild displacement not detected by current techniques. Secondly, it is more important to determine events close to the GEJ since this is where most pathologies occur including the adenocarcinoma.

Yeong Yeh Lee

School of Medical Sciences, Universiti Sains Malaysia Kubang Kerian, Kelantan, Malaysia

1. Wu JC, Mui LM, Cheung CM, Chan Y, Sung JJ. Obesity is associated with increased transient lower esophageal sphincter relaxation. Gastroenterology 2007;132:883-889.

2. Babaei A, Bhargava V, Korsapati H, Zheng WH, Mittal RK. A unique longitudinal muscle contraction pattern associated with transient lower esophageal sphincter relaxation. Gastroenterology 2008; 134:1322-1331.

3. Kim HI, Hong SJ, Han JP, et al. Specific movement of esophagus during transient lower esophageal sphincter relaxation in gastroesophageal reflux disease. J Neurogastroenterol Motil 2013;19:332-337.

4. Lee YY, Seenan JP, Whiting JG, et al. Development and validation of a probe allowing accurate and continuous monitoring of location of squamo-columnar junction. Med Eng Phys 2011;34:279-289.

5. Lee YY, Whiting JG, Robertson EV, et al. Kinetics of transient hiatus hernia during transient lower esophageal sphincter relaxations and swallows in healthy subjects. Neurogastroenterol Motil 2012;24:990, e539.

6. Lee YY, Whiting JG, Robertson EV, et al. Central obesity and waist belt cause partial hiatus hernia and short segment acid reflux in healthy volunteers. Gut 2013;62(suppl 1):A103-A104.

7. Pandolfino JE, Kim H, Ghosh SK, Clarke JO, Zhang Q, Kahrilas PJ. High resolution manometry of the EGJ: an analysis of crural diaphragm function in GERD. Am J Gastroenterol 2007;102:1056-1063.

8. Lee YY, Whiting JG, Robertson EV, Derakhshan MH, Smith D, McColl KE. Measuring movement and location of the gastroesophageal junction: research and clinical implications. Scand J Gastroenterol 2013;48:401-411.

9. Beaumont H, Bennink RJ, de Jong J, Boeckxstaens GE. The position of the acid pocket as a major risk factor for acidic reflux in healthy subjects and patients with GORD. Gut 2010;59:441-451.

10. Lee YY, McColl KE. Pathophysiology of gastroesophageal reflux disease. Best Pract Res Clin Gastroenterol 2013;27:339-351.

Conflicts of interest: None. 